\title{
Mobilized Mesenchymal Stem Cells for Tissue Engineering in Preclinical Models
}

\author{
Landa-Solís C, Olivos-Meza A, Ortega-Sánchez, Olivos-Diaz B, Velasquillo-Martínez C and Ibarra C* \\ National Rehabilitation Institute, Mexico City, Mexico
}

Received: August 08, 2015; Accepted: November 25, 2015; Published: January 04, 2016

*Corresponding author: José Clemente Ibarra-Ponce de León, National Rehabilitation Institute of Mexico,Mexico City, Mexico. 14389, Phone number: +52 555999 1000; ext: 19607/19609; E-mail: cibarra.corresponding@hotmail.com

\begin{abstract}
Background: Mesenchymal Stem Cells obtained from bone marrow are an alternative source of cells for tissue engineering. More studies are done with Mobilized Peripheral Blood Cells (MPBMSC) due to their plasticity on being able to be differentiated in mesenchymal tissues.
\end{abstract}

Objective:The objective of this study was to standarize the mobilization, isolation, and characterization process of mesenchymal stem cells obtained from peripheral blood in an animal model.

Methods: Four Suffolk sheep with ages of 2 years were mobilized using granulocyte colony-stimulating factor (G-CSF). Administration dose was $10 \mathrm{mg}$ per kilogram of body weight, applied in subcutaneous area every 24 hours, in three consecutive days. The mobilized cells were characterized by an antibody panel for surface markers (CD105, CD90, CD73, CD34, and CD45) and cultured in monolayer during 3 weeks.

Results: All population of leucocytes cells have similar behavior during day 1 to day 4 . We observed an improvement of populations at day 2 with maximum elevation at day 3 and decline at day 4 in the mobilized peripheral blood. Plastic adhesion and fibroblastic like morphology was observed in mobilized cells.

Conclusions: Is feasible to increase the mesenchymal stem cells number in peripheral blood with the three day administration of G-CSF. Isolated cells expressed the characteristic markers of mesenchymal stem cells by flow citometry.

Keywords: Mobilized peripheral blood; Mesenchymal stem cells; Tissue enginering

\section{Introduction}

Multipotent stem cells have the potential to differentiate into different lineages and may be the better source for tissue regeneration. Bone marrow mesenchymal stem cells (BMSCs) have emerged as a clinically relevant cell source for regenerative medicine, especially for cartilage repair, and also those cells have been suggested as a substitute for chondrocytes because of their signifcant proliferative and regenerative capacity. However, this cell source is problematic because of the morbidity and procedure risks. Fistable, this requires an extra surgycal procedure to harvest the bone marrow (BM) from the iliac crest. Second, pain is a residual symptom that could remain after procedure. To solve those problems, the advent of new sources of stem cells that offer high plasticity to repair different tissues with less invasive procedures is required. These have given rise to investigators turning toward the obtention of Mobilized Mesenchymal Stem Cells (MMSC) from Bone Marrow toward Peripheral Blood (PB) by means of treatment with the Granulocyte-colony stimulating factor (G-CSF) [1,2].

The effect is based on the negative modulation of Vascular adhesion surface molecule 1 (VCAM-1) and of nestin inhibition[3] in nestin-positive Mesenchymal stem cells (MSC)[4], localized in the vascular compartment of the BM niche. This mechanism favoring their release from the niche and their migration through intramedullary space toward the peripheral circulation, where obtaining these is easily accessible and less painful in comparison with iliac crest puncture $[5,6]$.

When mobilization occurs, two cell populations have been identified: Mobilized Hematopoietic Stem Cells (MHSC)[7] and Mesenchymal Stem Cells (MMSC)[8]. Mobilized hematopoietic stem cells have been characterized by means of surface markers such as CD133+, CD45+, CD34+, and CD38- [9,10], while mobilized mesenchymal stem cells are positive to CD105+, CD90+, CD73+, CD34-, and CD45 surface markers[9,11-13]. For the case of MMSC, their plasticity has been demonstrated on being differentiated in adipocytes, chondrocytes, and osteocytes[9,14-15].

The cell plasticity described for populations of MMSC possesses a good option for the development of new technology in animal models for tissue repair. Sheep due to its anatomical similarity with the human knee joint[16], is the ideal model for development of novel technology based on MMSC for the repair of damage such as cartilage lesions. Thus, the characterization of MMSC in culture in vitro is crucial for establishing a cellular differentiation model in sheep. Therefore, in the present work, we decided to characterize the effect of the culture in vitro on SC isolated from MPB in sheep by means of an antibody panel for the surface markers of Mesenchymal (MSC) and Hematopoietic stem cells (HSC). The aim of this study is to stablish a preclinical model of mobilization technique with the possibility to translate this procedure to humans. 


\section{Methods}

\section{Characteristics of the sheep's}

For this study, we employed four male Suffolk sheep, weighing between 60 and $70 \mathrm{~kg}$. Animals were stabled in the area designed for their adequate stay at the animal facility. Management of the sheep was developed establishing the clinical history of each sheep, describing in detail their state of health and body condition; these data was established on their admittance into the animal facility. All animals received human care in compliance with the "Guide for the Care and Use of Laboratory Animals" published by the National Institutes of Health (National Institutes of Health publication no.85-23, revised 1985)".

\section{Care and management of the sheep's}

For this study, we employed two male Suffolk sheep, weighing between 100 and $110 \mathrm{~kg}$. Animals were stabled in the area designed for their adequate stay at the animal facility. Management of the sheep was developed establishing the clinical history of each sheep, describing in detail their state of health and body condition; these data was established on their admittance into the animal facility. All animals received human care in compliance with the "Guide for the Care and Use of Laboratory Animals" published by the National Institutes of Health (National Institutes of Health publication no.85-23, revised 1985)".

\section{Bone marrow obtention}

For obtaining the bone marrow (MB) we used the a dose of acepromazine $0.1 \mathrm{mg} / \mathrm{kg}$ intra-venously (IV) as preanesthesia, following we using propofol with an anesthetic of short duration, at an initial dose of $1 \mathrm{mg} / \mathrm{kg}$ of weight by IV. The state of anesthesia it deepened by the continued administration of propofol at the same dose throughout the procedure. No discomfort in the animals was observed during proceeding. Jugular groove area was shaved; antisepsis of the area was conducted (with a solution of iodine and 70\% ethyl alcohol, washing 3 times). A 16G needle gauge taking into account the volume of the sample was collected $(20 \mathrm{~mL})$ was used for phlebotomy. The sample was poured into 4 sterile tubes $12 \times 75 \mathrm{~mm}$ with heparin. All the tubes were gently shaking before sending them to the laboratory for processing. After taking MPB sample, the sheep returns to his yard where it is monitored by the animal facility staff until recovery and received for three days with a dose of diclofenac sodium $5 \mathrm{mg} / \mathrm{kg}$ dose of body weight every 12 hours.

\section{Cell mobilization from bone marrow to peripheral blood.}

At two months after to BM obtention, each animal received three daily injections of G-CSF (Filgrastim; Amgen, Thousand Oaks, CA, USA) at a dose of $10 \mu \mathrm{g} / \mathrm{kg}$ Body weight. At day-four, Mobilized Peripheral Blood (MPB), was harvested from the jugular vein with a $20 \mathrm{ml}$ syringe previously heparinized (100 $\mathrm{IU} / \mathrm{mL}$ ).

In order to observe the behavior of leukocytes, granulocytes, monocytes, and lymphocytes a blood count control was performed from day 1 to day 4 .

\section{Isolation of mononuclear cells from BM and MPB.}

The mononuclear cells present in BM and MPB, were separated by means of the concentration gradient according to the following procedure: in a laminar flow hood (Forma Scientific), and each sample was placed in polypropylene tubes $(50-\mathrm{mL}$ capacity) for their centrifugation. Later, we carried out a 1:2 dilution with phosphate buffer solution (PBS) (Gibco Invitrogen), added with antibiotics/antimycotics at $1 \%$, Penicillin 10,000 UI, Streptomycin 10,000 $\mu \mathrm{g}$. We prepared $15 \mathrm{~mL}$ of Ficoll Paque (Amersham Biosciences, Piscataway, NJ, USA) in sterile, 50-mL polypropylene tubes (cat. \#CLS430829, Corning) and added 25 $\mathrm{mL}$ of the sample diluted in blood and PBS, utilizing the greatest care not to break the surface tension, in order to have a final volume of $40 \mathrm{~mL}$. Later, this was centrifuged at $300 \mathrm{~g}$ for $35 \mathrm{~min}$. Before to Isolation the mononuclear cells and after centrifuging these, we took the fraction of mononuclear cells and we produced $1 \times 10^{5}$ cells aliquots for characterization by flow cytometry (FC) and the mononuclear cells for primary culture (PC).

\section{Characterization by flow cytometry}

For the establish their immunophenotype, we used a aliquot of $2.5 \times 10^{4}$ cells in $100 \mu \mathrm{L}$ of PBS with $5 \mu \mathrm{L}$ of the antibody suspension and were left to incubate for $30 \mathrm{~min}$ at $4^{\circ} \mathrm{C}$. The monoclonal antibodies applied were CD34, CD45, CD90, CD117, CD73, CD166, CD105 y CD47 all from BD Pharmigen (California, USA). The samples and or unlabelled controls were included for each antibody and used to set the electronic gates on the flow cytometer. All data were obtained in a BD FACSCalibur flow cytometer and analyzed by Cell Quest PRO software (Becton Dickinson, USA) with a mean of 20,000 events.

\section{Culture of the stem cells}

An aliquot of $2.5 \times 10^{4}$ mononuclear cells were isolated from each of the BM and MPB was cultured, we used for the cell culture Dulbecco's Modified Eagle's Medium (DMEM; GibcoLife Technologies, USA) enriched with $20 \%$ adult sheep serum (SBA; BIO-WEST), which was added at $1 \%$ with the antibioticantimycotic (Gibco-Life Technologies), maintained in culture in an incubator at $37^{\circ} \mathrm{C}$ with $5 \%$ of $\mathrm{CO} 2$, in culture flasks of $25 \mathrm{~cm}^{2}$ for 3 weeks period until reaching $90 \%$ confluence.

\section{Statistical Analysis}

All data are expressed as mean and standard deviations (SD). Statistical analysis was performed with STATISTICA StatSoft v7 data analysis program. The results were compared with the entire cell surface markers expressed (CD34, CD90, CD117, CD73, CD105, CD 166 and CD47), direct from de MPB, after to isolation to mononuclear cells and three weeks of adherent cells in primary culture.

\section{Results}

All population of leucocytes cells has similar behavior during day 1 to day 4 . We observed an improvement of populations at day 2 with maximum elevation at day 3 and decline at day 4 in the mobilized peripheral blood (Fig. 1). 


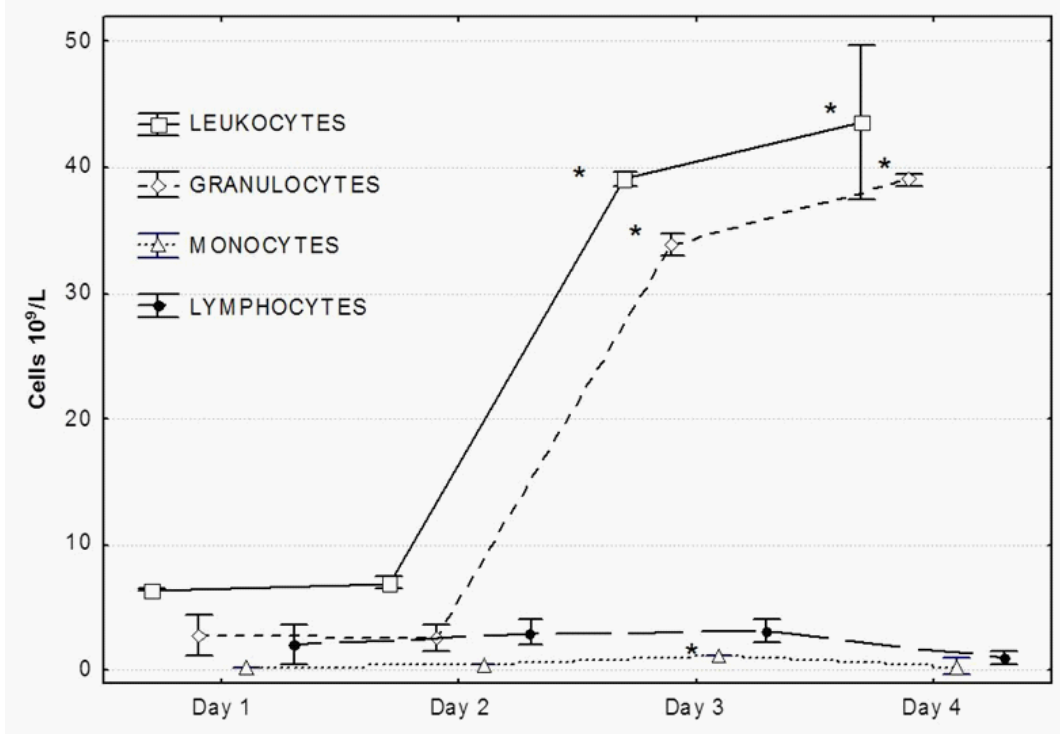

Figure 1: Behavior of the different populations of white cells during treatment with G-CSF in sheep.

From the 20-mL sample of BM we obtained a mean of $49 \times$ $10^{6} \pm 1.30$ mononuclear cells and from MPB we obtained at day- 4 after the first dose of G-CSF, a mean of $16.6 \times 10^{6} \pm 0.18$ mononuclear cells we obtained. After 2-weeks of primary culture (PC) of the mononuclear cells, two layers of cells in the same dish culture we observed: the first layer adhered in the bottom of the dish plate comprised cells with elongated morphology that were positive for immunofluorescence at PB-MSC markers (CD73+, CD90+, and CD105+) while the second population, adhered over the first monolayer, had a rounded morphology and was positive for PB-HSC markers and mature hematopoietic cells (CD34+ and CD45, respectively) respectively. At week 3 of PC, the predominant cellular morphology was fibroblastoid (Fig. 2).

The result obtained for the whole blood immunophenotype at day- 4 with G-CFS was the following: CD34: $1.3 \% \pm 1.2$; CD 45 : $1.4 \% \pm 0.5 ; \mathrm{CD} 73: 1 \% \pm 0.7 ; \mathrm{CD} 90: 4.0 \% \pm 2.0$, and CD105: $0.7 \%$ \pm 0.2 . The immunophenotype obtained after separation of the mononuclear cells with Ficoll was as follows: CD34: $5.9 \% \pm 1.7$; CD45: $5.5 \% \pm 1.4 ;$ CD73: $4.0 \% \pm 1$; CD90: $3.9 \% \pm 1.5$, and CD105: $4.4 \% \pm 1.6$, and at three weeks of PC, the immunotype obtained was the following: CD34: $2.4 \% \pm 0.3$; CD45: $4.1 \% \pm 2.1$; CD73: 27.2\% \pm 0.3; CD90: $47.4 \% \pm 1.3$, and CD105: $43.4 \% \pm 3.7$ (Fig. 3 ).

Comparing the means with the Mann-Whitney $U$ test from the superficial marker readings of the sample of whole blood compared with mononuclear cells isolated by means of the Ficoll gradient, an increase in the counts without statistical significance was observed. However, comparing the means from separation with the Ficoll gradient versus cells in PC after 3 weeks, we found a statistically significant increase for PB-MSC markers of CD73, CD90, and CD105, and a statistically significant diminution for mature hematopoietic cell markers and PB-HSC (CD45 and CD34), respectively.

\section{Discussion}

We observed that mononuclear cells isolated with Ficoll from MPB in sheep that got adhered to the plastic at week-2 of culture acquired fibroblast-like morphology in addition to positivity for markers CD73+, CD90+, and CD105+, which have been described as MSC markers. These markers have been found in MSC isolated in diverse tissues, such as Bone marrow (BM) [17], follicular ovarian cells[18], adipose tissue[19], umbilical cord cells[20], dental pulp [21], amniotic fluid[22], and corneal limbus[23]. MSC are present in a great part of the tissues in adult individuals with the function of regenerating the different cells of the organism[24]. The presence of MSC in such varied tissues speaks to the capacity of MSC to adapt to diverse conditions of supplying nutrients that, according to the case in which they are localized, can be of high nutrient content, such as in the corneal limbus. In our work, we employed a standard culture medium (Dulbecco's modified Eagle's medium [DMEM]) supplemented only with adult sheep serum, and we demonstrated that even under this basis nutrient condition for MSC isolated from MPB (CD90+ at culture initiation, 3.9\%, and at week 3 of culture, $47.4 \%$ ), they are capable of growing and proliferating in comparison with PB-HSC that, at week 3 of culture, only $2.4 \%$ of CD34+ achieved adaptation (Figure 3 ). It has been described that the culture of HSC is carried out under suspension due to their poor adherence to the surface of the culture in vitro[25,26]; however, it was reported that in umbilical cord-isolated stem cells, there is a population of CD34+/CD45+ cells that do not present the fibroblastoid morphology characteristic of MSC and that they proliferate in two-dimensional cultures on the monolayer formed by adhered MSC, deriving from umbilical cord blood. The latter cellular population (CD34+/CD45+) has been identified as endothelial cell precursors, due to that endothelial and hematopoietic cell possess a bipotent progenitor in common, 


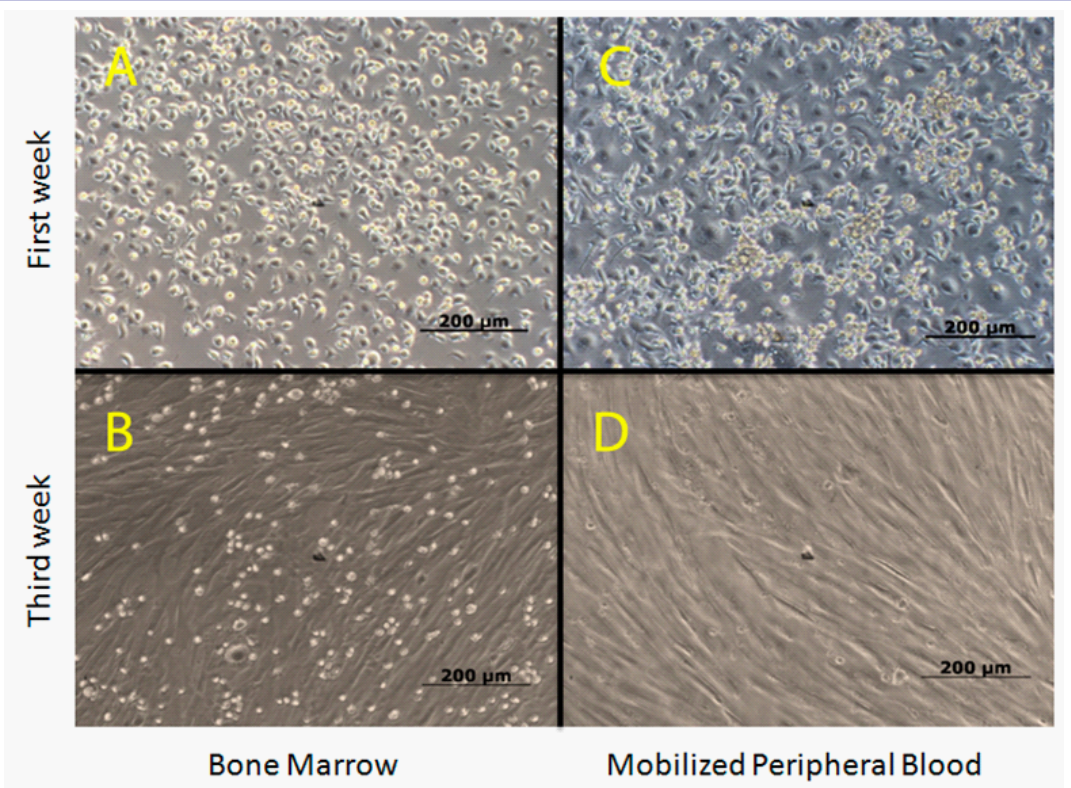

Figure 2: Representative visible-light microscopy fotomicrographs showing cells isolated from BM (A), first week in cell culture, (B) tree week in cell culture and MPB (C), first week in cell culture and (D), tree week in cell culture.
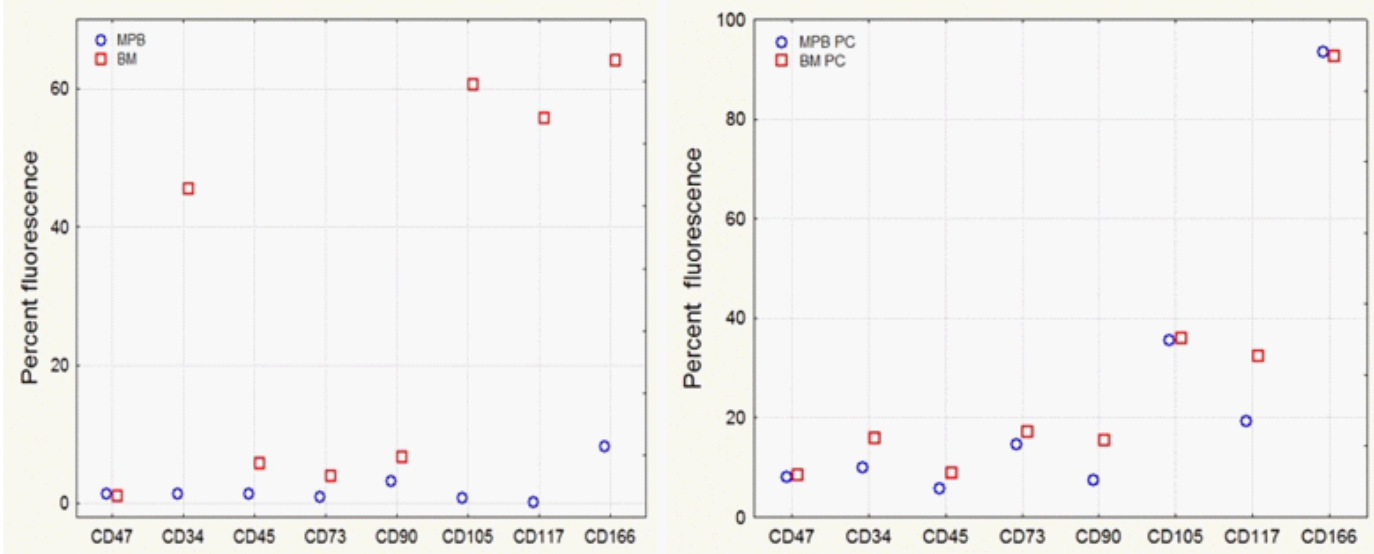

Figure 3: Immunophenotype comparation of isolated mesenchymal stem cells from Bone Marrow and Mobilized Peripheral Blood at harvesting day and at 3 weeks of cell culturing.

denominated the hemangioblast, localized at the embrionary level in the caudal mesoderm[27,28]. According to our results, we suppose that this CD34+/CD45+ population of endothelial precursor cells is found present in our cultures at a minimal proportion of $<2.4 \%$, proliferating on the PB-MSC monolayer.

Our results indicate that it is feasible to isolate a PB-MSC population employing a standard culture medium supplemented only with adult sheep serum, and that PB-MSC obtained possess, according with the expressed immunophenotype.

\section{Conclusion}

It is feasible to isolate MSC from MPB and to expand them in vitro without the need of culture media and specialized highcost cellular isolation systems. This model can be employed in the field of Orthopedics for the development of novel technology in the regeneration of joint cartilage.

\section{Acknowlegement}

This work is supported by the Mexican Council of Science grant (CONACyT) SALUD-2011-1-241 162387, PDCPN-2013-01-215138; Technology, Science and Innovation Secretary Grants: SECITI 242079 BIS/2013 and SECITI/INR/ GOB-25/2013.

\section{References}

1. Chao NJ, JR Schriber, Grimes K, Long GD, Negrin RS, Raimondi CM, et al. "Granulocyte colony-stimulating factor "mobilized" peripheral blood progenitor cells accelerate granulocyte and platelet recovery after high-dose chemotherapy." Blood. 1993;81(8):2031-2035.

2. Schmitz N, M Beksac, Bacigalupo A, Ruutu T, Nagler A, Gluckman E, et al. "Filgrastim-mobilized peripheral blood progenitor cells versus 
bone marrow transplantation for treating leukemia: 3-year results from the EBMT randomized trial." Haematologica. 2005;90(5):643648.

3. Hopman RK and JF DiPersio. "Advances in stem cell mobilization." Blood Rev. 2014;28(1):31-40. doi: 10.1016/j.blre.2014.01.001. Epub 2014 Jan 14.

4. Sousa BR, RC Parreira, Fonseca EA, Amaya MJ, Tonelli FM, Lacerda $\mathrm{SM}$, et al. "Human adult stem cells from diverse origins: an overview from multiparametric immunophenotyping to clinical applications."Cytometry A. 2014;85(1):43-77. doi: 10.1002/ cyto.a.22402. Epub 2013 Nov 25.

5. Sahin AO and M Buitenhuis. "Molecular mechanisms underlying adhesion and migration of hematopoietic stem cells." Cell Adh Migr. 2012;6(1):39-48. doi: 10.4161/cam.18975.

6. Salvucci O, K Jiang, Gasperini P, Maric D, Zhu J, Sakakibara S, et al. "MicroRNA126 contributes to granulocyte colony-stimulating factorinduced hematopoietic progenitor cell mobilization by reducing the expression of vascular cell adhesion molecule1." Haematologica. 2012;97(6):818-826.doi: 10.3324/haematol.2011.056945. Epub 2012 Jan 22.

7. Gallardo E, A Garcia, Ramón C, Maraví E, Infante J, Gastón I. “CharcotMarie-Tooth disease type 2J with MPZ Thr124Met mutation: clinico-electrophysiological and MRI study of a family." J Neurol. 2009;256(12):2061-2071. doi:10.1007/s00415-009-5251-y.

8. Fu WL, CY Zhou, Yu JK. "A new source of mesenchymal stem cells for articular cartilage repair: MSCs derived from mobilized peripheral blood share similar biological characteristics in vitro and chondrogenesis in vivo as MSCs from bone marrow in a rabbit model." Am J Sports Med. 2014;42(3):592-601. doi: 10.1177/0363546513512778. Epub 2013 Dec 10.

9. Jin P, E Wang, Ren J, Childs R, Shin JW, Khuu H, et al. "Differentiation of two types of mobilized peripheral blood stem cells by microRNA and cDNA expression analysis." J Transl Med. 2008;6:39. doi:10.1186/1479-5876-6-39.

10. Azouna NB, L Berraeis, Regaya Z, Jenhani F. "Immunophenotyping of hematopoietic progenitor cells: Comparison between cord blood and adult mobilized blood grafts." World J Stem Cells. 2011;3(11):104112. doi:10.4252/wjsc.v3.i11.104.

11. Thomasson B, L Peterson, Thompson J, Goerner M, Kiem HP. “Hum Gene Ther. 2003;14(17):1683-1686.

12. Villa-Diaz LG, SE Brown, Liu Y, Ross AM, Lahann J, Parent JM, et al. "Derivation of mesenchymal stem cells from human induced pluripotent stem cells cultured on synthetic substrates." Stem Cells. 2012;30(6):1174-1181. doi:10.1002/stem.1084.

13. Rammal H, J Beroud, Gentils M, Labrude P, Menu P, Kerdjoudj H, Velot E. "Reversing charges or how to improve Wharton's jelly mesenchymal stem cells culture on polyelectrolyte multilayer films." Biomed Mater Eng . 2013;23(4):299-309. doi: 10.3233/BME-130754.

14. Tondreau T, N Meuleman, Delforge A, Dejeneffe M, Leroy R, Massy $\mathrm{M}$, et al. "Mesenchymal stem cells derived from CD133-positive cells in mobilized peripheral blood and cord blood: proliferation, Oct4 expression, and plasticity."Stem Cells. 2005;23(8):1105-1112.

15. Calloni R, GS Viegas, Türck P, Bonatto D, Pegas Henriques JA. "Mesenchymal stromal cells from unconventional modelorganisms."Cytotherapy. 2014;16(1):3-16.doi: 10.1016/j. jcyt.2013.07.010. Epub 2013 Oct 8.
16. Pape D and H Madry."The preclinical sheep model of high tibial osteotomy relating basic science to the clinics: standards, techniques and pitfalls." Knee Surg Sports Traumatol Arthrosc. 2013;21(1):228236. doi: 10.1007/s00167-012-2135-y. Epub 2012 Jul 21.

17. Screven R, E Kenyon, Myers MJ, Yancy HF, Skasko M, Boxer L, et al. "Immunophenotype and gene expression profile of mesenchymal stem cells derived from canine adipose tissue and bone marrow." Vet Immunol Immunopathol. 2014;161(1-2):21-31. doi:10.1016/j. vetimm.2014.06.002. Epub 2014 Jul 1.

18. Riva F, C Omes, Bassani R, Nappi RE, Mazzini G, Icaro Cornaglia A, et al. "In-vitro culture system for mesenchymal progenitor cells derived from waste human ovarian follicular fluid." Reprod Biomed Online. 2014;29(4):457-469 doi: 10.1016/j.rbmo.2014.06.006. Epub 2014 Jul 5.

19. Dudakovic A, E Camilleri, Riester SM, Lewallen EA, Kvasha S, Chen $\mathrm{X}$, et al. "High-resolution molecular validation of self-renewal and spontaneous differentiation in clinical-grade adipose-tissue derived human mesenchymal stem cells."J Cell Biochem. 2014;115(10):18161828. doi:10.1002/jcb.24852.

20. Qiu Y, MM Yun, Han X, Zhao R, Zhou E, Yun S, et al. "Human umbilical cord mesenchymal stromal cells suppress MHC class II expression on rat vascular endothelium and prolong survival time of cardiac allograft." Int J Clin Exp Med. 2014;7(7):1760-1767

21. Davies OG, AJ Smith, Cooper PR, Shelton RM, Scheven BA. "The effects of cryopreservation on cells isolated from adipose, bone marrow and dental pulp tissues." Cryobiology. 2014;69(2):342-347. doi: 10.1016/j.cryobiol.2014.08.003. Epub 2014 Aug 12.

22. Rossi B, B Merlo, Colleoni S, Iacono E, Tazzari PL, Ricci F, et al. "Isolation and in Vitro Characterization of Bovine Amniotic Fluid Derived Stem Cells at Different Trimesters of Pregnancy." Stem Cell Rev. 2014;10(5):712-724. doi: 10.1007/s12015-014-9525-0.

23. Landa-Solis C, L Vazquez-Maya, Martínez-Pardo ME, Brena-Molina AM, Ruvalcaba E, Gómez R, et al."Use of irradiated human amnion as a matrix for limbal stem cell culture." Cell Tissue Bank. 2013;14(1):7784. doi: 10.1007/s10561-012-9302-8. Epub 2012 Mar 7.

24. Bianco P, PG Robey, Simmons PJ . "Mesenchymal stem cells: revisiting history, concepts, and assays." Cell Stem Cell. 2008;2(4):313-319. doi: 10.1016/j.stem.2008.03.002.

25.Sakashita K, I Kato, Daifu T, Saida S, Hiramatsu H, Nishinaka Y, et al. "In vitro expansion of CD34CD38 cells under stimulation with hematopoietic growth factors on AGM-S3 cells in juvenile myelomonocytic leukemia." Leukemia. 2014;29(3):606-614. doi: 10.1038/leu.2014.239. Epub 2014 Aug 8.

26. Wiekmeijer AS, K Pike-Overzet, Brugman MH, Salvatori DC, Egeler RM, Bredius RG, et al. "Sustained Engraftment of Cryopreserved Human Bone Marrow CD34(+) Cells in Young Adult NSG Mice." Biores Open Access. 2014;3(3):110-116. doi: 10.1089/biores.2014.0008.

27. Pelosi E, G Castelli, Martin-Padura I, Bordoni V, Santoro S, Conigliaro A, et al. "Human haemato-endothelial precursors: cord blood CD34+ cells produce haemogenic endothelium." PLoS One. 2012;7(12):e51109. doi:10.1371/journal.pone.0051109. Epub 2012 Dec 4.

28. Lin CS and TF Lue. "Defining vascular stem cells." Stem Cells Dev. 2013;22(7):1018-1026. doi: 10.1089/scd.2012.0504. Epub 2013 Jan 18. 